\title{
Shared understandings, collective autonomy, and global equality
}

\author{
Chris Armstrong* \\ School of Social Sciences, University of Southampton, Southampton, UK
}

\begin{abstract}
The political theorist Michael Walzer has usually been taken as an opponent of global distributive justice, on the basis that it is incompatible with collective autonomy, would endanger cultural diversity, or simply on the basis that principles of global distributive justice cannot be coherently envisaged, given cross-cultural disagreement about the nature and value of the social goods that might be distributed. However in his recent work, Walzer demonstrates a surprising degree of sympathy for the claims of global distributive justice, even of the egalitarian variety. But the precise contours of his current position on global equality are not yet clearly developed. The paper, therefore, attempts to reconstruct what that position might be, paying particular attention to the conclusions we could draw firstly for our understanding of the opposition between global equality and national self-determination (which is more complex than has sometimes been thought), and secondly for the relationship between global equality and shared understandings.
\end{abstract}

Keywords: global equality; global justice; collective autonomy; shared understandings; Michael Walzer

The relationship between the claims of global distributive justice, national selfdetermination, and cultural diversity has attracted much attention recently. Three of the most commonly voiced objections to global distributive justice - and especially, on some accounts, the egalitarian variety - are first that it is incompatible with respecting the collective autonomy (and responsibility) of national communities; second that it cannot be achieved without endangering cultural diversity, perhaps even crushing it in instituting the kind of global state that egalitarian justice might require; and third that articulating and/or implementing principles of equality at the global level simply cannot be done. On this last view, we have no metric at the global level by way of which to judge whether resources or opportunities, for example, are equally held, given that different communities differ in the way they conceive and value the goods they distribute amongst themselves. John Rawls, for example, levelled the first and second of these charges, whereas David Miller has more recently levelled the first and the third. ${ }^{1}$

${ }^{\star}$ Correspondence to: Chris Armstrong, School of Social Sciences, University of Southampton, Southampton, UK. Email: c.armstrong@soton.ac.uk 


\section{Armstrong}

In descriptions of this broadly sceptical camp, we usually find Michael Walzer. Indeed in international relations theory in particular he seems to figure as the 'communitarian' theorist par excellence, and someone to range against the opposite pole of 'cosmopolitanism'. He is certainly often identified with the three claims mentioned above - indeed when Miller wants to raise the third, 'metric' objection to global egalitarianism, he tends to cite Walzer as a source of inspiration. ${ }^{2}$ Beyond his pathbreaking work on just war theory, the one thing many people seem to 'know' about Walzer is that he rejects both the need for and the possibility of global distributive justice. This paper aims to unsettle that identification. The image of Walzer as the adamant critic of global distributive justice neglects the fact that in his most recent work Walzer demonstrates a surprising degree of sympathy for the claims of global justice, even of the egalitarian variety. But the precise nature of his position on global equality remains to be explained, as do the lessons we might learn from it. The paper, therefore, examines the contours of Walzer's position, paying particular attention to the conclusions those interested in global justice might draw in order to better understand firstly the opposition between global equality and national selfdetermination (which is more complex than has sometimes been thought), and secondly the relationship between global equality and shared understandings. Since Walzer has not written at length on the topic, and since what he has published remains rather discursive and allusive - though, as always, elegant and in its own way compelling - this cannot be a simple process of connecting the dots. Instead, the project must be one of reconstructing a position that could square his more recent comments with his earlier reasons for reticence about global equality. One possible conclusion is that there is no coherent way of reconciling the two, in which case the project is entirely recondite. But the present paper resists that view, and attempts to unite the commitments - in the belief that in so doing, we might understand the challenge to global equality better.

\section{WALZER ON UNIVERSALISM}

As is well known, contemporary debates about issues of distributive justice were given an enormous fillip by the publication of John Rawls's $A$ Theory of Fustice in the 1970s. This work presented a sophisticated argument for a broadly egalitarian form of distributive justice, according to which goods should be distributed between citizens according to a series of principles designed to integrate claims such as equality of opportunity and priority to the worst off in society. ${ }^{3}$ Less clear, at that time, were the implications for questions of global justice. But many of Rawls's most ardent followers were sure that the work did have implications and that they were radical ones. Styling themselves as 'cosmopolitans', they suggested that the nation into which one was born was a matter of brute luck and that one's life-chances should not suffer as a result of it. Borders are at best of derivative moral significance, whereas the result of sustained reflection on questions of international morality should be the advocacy of principles of global distributive justice. ${ }^{4}$ Examples included a 
'Global Difference Principle' that would tailor the distribution of a variety of goods to meet, first and foremost, the interests of the worst off in the world. Less ambitious but, still, highly challenging principles would seek to ensure that all communities had access to a fair share of natural resources, or that the subsistence needs of all inhabitants of our world were met as a matter of priority. ${ }^{5}$

Recent years have seen a proliferation of literature about global distributive justice and about cosmopolitanism, and a series of proposals for distributive principles that would have properly global scope. But not everyone within the academy has been convinced. John Rawls was not, much to the disappointment of his erstwhile supporters. ${ }^{6}$ Neither, on most accounts, was Michael Walzer. In this section I will show why Walzer might be assumed to be predisposed against ideals of global distributive justice - although towards the end of the section I will suggest that his opposition has not been entirely straightforward.

For Walzer, by stark contrast to many contemporary cosmopolitans, justice is 'a social invention, variously made'. ${ }^{7}$ Theories of distributive justice must take account of divergent social meanings; intelligible principles of distributive justice can only be worked up with due reference to how different communities in fact conceive and value the social goods that they distribute amongst themselves. To put it most strongly, all arguments about justice are simply appeals to common meanings. ${ }^{8}$ Egalitarians, for instance, work up their arguments for socio-political reform from the ideas already present in their own political cultures, and not from some 'external' source: 'Moral and intellectual reform begins with intra-hegemonic struggle ... it is in large part a rearrangement of ideas already present in the old [system]'. Any culture is likely to provide resources for social criticism, simply in virtue of the fact that elites tend to promise us more in the way of equality (or freedom, or justice) than they actually deliver-equality typically has a 'real but distinctly limited value' in the hegemonic culture, but it also has larger, 'utopian' meanings that are occasionally invoked within that hegemonic culture and that allow for radical criticism on the part of the disaffected. ${ }^{9}$ Indeed all radical change has arisen from the kind of 'organic' social criticism whereby regimes are called upon to practice what they preach, or to deliver on their promises. ${ }^{10}$

By contrast to this model of 'internal' social criticism, Walzer opposes the kind of philosophical 'abstraction' typified by the search for transcendental principles external to the shared understandings of a given community. ${ }^{11}$ If such transcendental principles are 'discovered', a higher status will usually be claimed for them when compared to everyday common understandings. The problem is that this mode of accessing moral principles slides too easily into authoritarianism, whereby the values of the community are ridden over rough-shod as the newly discovered 'truth' is implemented (it is, after all, the truth). It is usually taken as a consequence of this view that global distributive justice is simply unintelligible (given that we do not agree, globally, on the meaning of the social goods that might be distributed), and that any attempt to impose it from without will be unjust by definition. Certainly philosophical 'authoritarianism', whereby communities might be governed by ideals not shared by them, is at least as much of a danger globally as it is domestically. ${ }^{12} \mathrm{But}$ 


\section{Armstrong}

this does not mean that Walzer is not a universalist on justice. In fact he distinguishes between two forms of universalism, which he calls 'covering-law' and 'reiterative universalism'. The first suggests (in the mode of abstraction) that there is from the outset a single moral law, which is accessible to reason and ought, when found, to be imposed upon all-regardless of their actual beliefs. On the second view, the content of any universal morality is precisely those principles that empirically speaking are common to diverse communities. Elucidating what is universal is a descriptive exercise insofar as it entails delineating the overlaps between the shared understandings of distinct communities. The first form of universalism will impose 'external' constraints on any community, whereas the second, properly understood, imposes only 'internal' constraints. ${ }^{13}$ Philosophical authoritarianism is not a danger here, because the social critic is only interpreting what is already present in a political culture. No special status is presumably to be claimed for that interpretation, beyond pointing to its coherence. So Walzer is a universalist in this second sense.

This has clear implications for ethics in the international domain. When sketching the principles of global justice, we must work on the basis of what is already present and reiterated across cultures; but we should not expect too much convergence. To use one of Walzer's well-known metaphors, globally there is a common convergence on a 'thin' set of issues concerning human rights and the conduct of war ('The principles of political independence and territorial integrity do not protect barbarism $^{14}$ ), but also extending to prohibitions against murder, deception, and cruelty. But 'thick' common meanings (such as would be needed to underpin a fully fledged scheme of distributive justice) are just not present at the global level. As Walzer puts it, 'were we to take the globe as our setting, we would have to imagine what does not yet exist. ... We would have to imagine a common set of meanings' ${ }^{15}$ Implementing such imagined common meanings would, by extension from the argument above, witness a slide into authoritarianism. Attempts to secure global distributive justice would not secure broad agreement, and might instead require an authoritarian state at the global level; and it is hard to envisage how a global state could be compatible with cultural diversity. ${ }^{16}$

Walzer's arguments here have been controversial, but they also resonate with some more recent criticisms of (at least some visions of) global distributive justice. Rawls's position in The Law of Peoples is redolent of Walzer's in a number of ways. Whereas Rawls is keen to assure us that his eight principles of the Law of Peoples are 'familiar and traditional', given 'the [shared] history and usages of international law and practice', he is just as determined to remind us that the global public political culture, such as it exists, does not provide the much denser stock of shared ideas necessary to get a conception of global distributive justice off the ground. ${ }^{17}$ In the face of this, the imposition of global distributive justice would violate a fundamental norm of legitimacy: that principles of justice must be acceptable, or reasonably acceptable, to the people they will govern. ${ }^{18}$ Though it is not employed by Rawls, the language of thick and thin could easily have been applied here (the principles of the Law of Peoples can be derived from a thin global consensus; support for global distributive justice cannot). More specific opprobrium has recently been levelled by David Miller 
at the idea of egalitarian global justice. Such an idea, Miller tells us, neglects to recognise that communities will legitimately define and distribute social goods in different ways; in fact, no overall ranking of resources or opportunities is available that would enable us to declare that global equality had been satisfied. In view of this, global egalitarian justice in particular is, barring extensive cultural homogenisation, a chimera. ${ }^{19}$ Indeed when global egalitarians have gotten specific about the implications of their views - as have some advocates of global equality of opportunity —other critics have reiterated much the same point. ${ }^{20}$

Despite this, the picture of Walzer as a stalwart opponent of global distributive justice was always a simplistic one. One early instance of sympathy for its claims comes during the well-known discussion of the ethics of immigration. Though he does want generally to argue for the right of communities to determine who might or might not enter their borders, he also admits the moral force of Henry Sidgwick's claim that 'a state possessing large tracts of unoccupied land [could not reserve] an absolute right of excluding alien elements'. ${ }^{21}$ Discussing Australia's 'whites only' immigration policy, he admits a tension between the right of collective selfdetermination that he (generally) argues for, and the intuitive appeal of an argument linking the obligation to admit immigrants to the availability of space (and also, Walzer adds, resources); he appears unsure how to adjudicate between the two moral claims. In this particular case what is at stake is very specific: the legitimacy of refusing to admit non-white immigrants, rather than immigrants per se, to a rich and spacious country. And it is not claimed that in this case Australia has an obligation to admit immigrants in relation to its excess land: its leaders could legitimately choose between admitting diverse immigrants into its existing territory, ceding excess land, and remaining culturally (relatively) homogenous. But the claim that nation-states can possess resources that are in excess of what is needed, in the face of pressing need elsewhere, ${ }^{22}$ has by now been raised and cannot easily be dispensed with. Walzer suggests that some of this 'excess' of resources will need to be redistributed: not all of it, so that 'simple equality' resulted at the global level, but something short of that which would still allow, and inevitably result, in different levels of wealth between political communities. But this is to admit the possibility that principles of global distributive justice might properly function, at least in a negative way, to criticise existing distributions. Whilst Walzer has not argued that they might have a positive role in delineating solutions cashed out in terms of duties of global distributive justice, that can of worms has at least been raised as an issue here. What form should global redistribution take and how should we set its goals and parameters? This is a difficult question, since much of Spheres of fustice has been devoted to establishing that cross-community metrics of resources are not available to us: how then to judge the level of excess and the level of entitlement? These questions are not pursued, and Walzer claims that the form of the redistribution can be 'fixed by some version of collective mutual aid'. ${ }^{23}$ But the claim that some kind of 'distributive justice [is required] on a global scale' has been raised and not refuted decisively by any means. The question only achieves further attention in Walzer's more recent writings, to which we now turn. 


\section{Armstrong}

\section{SECURING GLOBAL EQUALITY}

As is well known, Walzer has in recent years become more willing to call for military intervention to defend against gross human rights violations. He has not dropped the presumption against intervention, but he has 'found it easier and easier to over-ride the presumption', ${ }^{24}$ partly by expanding the category of abuses that presumably infringe the minimalist universal moral code sufficiently to trump the claims of collective autonomy. As part of that process, he has also argued more explicitly for the establishment or entrenchment of various global institutions, including a world criminal court with powers of arrest, and a United Nations with genuine powers of military intervention. ${ }^{25}$

But the shift in position on global distributive justice is more pertinent to our purposes here and more intriguing. Originally, in Spheres of fustice, Walzer gave the impression (his comments of justice and immigration cited above notwithstanding) that there could be no global distributive justice, because we could not agree on what that meant in practice, given cultural pluralism. There has never been a universal 'currency' of distributive justice, because of the different ways in which different cultures have understood the social goods they distribute amongst themselves. Nevertheless in his recent work, Walzer recognises that the most drastic forms of degradation and inequality occur in international society, and that there is a 'global hierarchy' that needs tackling. ${ }^{26}$ This hierarchy can be understood, at least partially, in a distributive sense. When evaluating the various contenders for an international regime of governance (ranging from a world state to international anarchy), Walzer suggests four criteria for judging them: (global) distributive justice, individual freedom, cultural pluralism, and the promotion of peace. ${ }^{27}$ We learn little at this stage about how to balance these priorities together (though see the section "Global egalitarianism and national self-determination"), but in any case principles of distributive justice are now presented as one important criterion for the evaluation of a regime of global governance. It is reiterated that a world state would be undesirable, but at the same time it is conceded that its ability to pursue global distributive justice, and 'egalitarian reforms' specifically, would be one thing that counted in its favour. ${ }^{28}$

On his current presentation, greater global equality - for individuals as well as communities - is other things being equal a desirable goal. It might be thought here that what Walzer is surely defending is a purely nation-regarding form of global egalitarianism, which seeks only to secure a kind of parity between national communities, so that they might be free from domination by each other, and might be able to operate on a kind of internationally just playing-field. That, after all, would accord somewhat better with his erstwhile defence of collective autonomy. But we must be clear, in fact, that Walzer transcends this position by describing efforts to reduce inequalities between individuals on a global scale. The kind of reform that a stronger global institution would be able to enact would include, for example, the establishment of universal labour standards or the redistribution of resources across borders. ${ }^{29}$ As we will see below, instead of a world state, Walzer's preferred vision is one of a world of well-governed states - but that vision is at least partly attractive 
because it serves the goal of narrowing individual-regarding global inequalities. It is suggested that the autonomy of nation-states is to be defended (amongst other reasons) because it serves that end: entrenching state power (at least for some states) is likely to get us closer to global equality than any alternative strategy. On Beitz's famous distinction, this sounds very much like cosmopolitanism about morality but not about institutions. ${ }^{30}$

Walzer's global approach is presented as an outgrowth of, or at least a parallel case to, his approach to the politics of multiculturalism. He has long argued that a satisfactory theory of equality must be liberal in its basic intuitions; indeed, his theory of complex equality represents an exercise in extending the liberal 'art of separation' onto the terrain of distributive justice. ${ }^{31}$ But he has also long argued that liberalism is incomplete as a political theory, and one important reason for this is that it pays insufficient attention to our associational life and our life as members of communities, institutions, and groups. This after all forms the substance of the periodic 'communitarian correction' of liberalism on his view. Rather than communitarianism representing a genuine competitor to liberalism, various versions of the communitarian challenge to liberalism have emerged at different times to correct one of its key defects: its stubborn treatment of individuals outside of their associational context. But for Walzer this myopic form of liberalism is self-defeating, because individuals do live their lives in associational contexts that any adequate theory of justice must attend to. For this reason a viable egalitarian politics will be liberal, but it will not be exclusively liberal. In terms of domestic egalitarian politics, liberalism is characterised by an 'emancipatory' model, which focuses on granting equal opportunities to individuals, broadly speaking regardless of their group membership. But according to Walzer the goals of the emancipatory model - though though laudable - cannot effectively be secured by an approach that focuses on granting opportunities to individuals but neglects the groups to which they belong. We should pay attention to the groups individuals are members of if we want to actually secure equality effectively. This is not because groups matter morally; it is a matter chiefly of political efficacy. In practice, delivering on the promise of equality means supplementing the emancipatory model with a model of 'empowerment', The empowerment model is a necessary correction or, better, supplement to the emancipatory model. It focuses on building the capacities, autonomy, and security of the groups to which individuals belong. ${ }^{32}$ This focus is important because oppressed groups often suffer from stigma, exclusion, and marginalisation, and political remedies may need to be finely tailored to overcome those specific evils.

This is not to say, though, that empowerment will be achieved by a politics of 'recognition', simply understood. Rather than arguing directly for the eradication of the stigma felt by oppressed groups, Walzer believes that the removal of stigma will likely be achieved indirectly as a result of a given group's achievement of material security, political resources, and institutional stability. ${ }^{33}$ On the empowerment model, then, though the goal remains the attainment of equal opportunities or resources for individuals, the achievement of this depends on strengthening, rather than ignoring, the groups to which we belong. For it is once the groups to which we 


\section{Armstrong}

belong have a secure material basis, that self-respect and broader social respect might be expected to follow. This is why Walzer calls his multiculturalism a 'meatand-potatoes' (rather than, for instance, a recognition-based) variety: 'the material strength of groups [the safeguarding of the meat and potatoes of their collective life] compels their mutual respect'. This material strength contributes to the sense of efficacy of a group's members, and provides a much surer route towards the liberal goal of equality. ${ }^{34}$

The relationship between the emancipation and empowerment models is clear: whereas the former supplies the moral goals, the latter supplies the strategy. Significantly, Walzer depicts his position on global justice as a more or less straightforward extension of this 'meat-and-potatoes' model of multiculturalism to the global scale. Unfortunately, Walzer claims, cosmopolitans tend to simply reproduce the emancipatory model at the global level and show no concern for the fact that global equality for individuals - whilst unquestionably a key normative goal-requires us, at the level of strategy, to empower them via strengthening the groups to which they belong. ${ }^{35}$ As such liberal cosmopolitan theories, as currently understood, appear incapable of delivering on their goals. ${ }^{36}$ Like the domestic emancipatory model, they are seen as toothless in a world characterised by intense feelings of belonging and identity - which should be used as tools for achieving justice and not seen as mere obstacles to it. Global equality will not, in fact, be served by a simple jump forwards to purely global institutions, though such institutions are certainly (non-exclusively) necessary. Rather, according to Walzer, the delivery of equality at the global level involves a two-track process, whereby on the one hand global institutions are created that can regulate the environment, trade, labour, and resources, but on the other hand weak states are themselves strengthened. We certainly do need to move in the direction of further political centralisation, and civil society organisations such as global political parties, global unions, and global movements pursuing, for instance, gender equality can play a role in this ${ }^{37}$ as can regional associations such as the European Union. The present state system cannot provide an adequate response to all of the inequalities that characterise the contemporary world.

But we also need to strengthen states at the same time - at least states that, at present, are not capable of delivering meat and potatoes to their citizens. Thus, as with the domestic brand of multicultural politics, it is clear that ' $[t]$ he terrible poverty of so many people, in the third world especially, cannot be addressed without attending to the groups to which they belong, ${ }^{38}$ In the long-term, global equality will only be served by securing 'an empowered and effective state' for all individuals. ${ }^{39}$ The 'empowerment' model suggests a two-track strategy because what is needed is not only the addition of an additional layer of governance alongside the existing, imperfect state system, but also the simultaneous fulfilment of the ideal of a world of capable, functioning states. The idea that 'a completed universalised state system' is imperative is not new to Walzer, ${ }^{40}$ and neither is the idea that its completion might place obligations on the rich - though he now goes so far as to suggest that Thomas Pogge's Global Resources Dividend is an example of the kind of mechanism that 
could usefully achieve the resource flows necessary to deliver on this vision. ${ }^{41}$ But the idea that this is somehow an agent of global egalitarianism is a new and significant emphasis.

Thus a 'meat-and-potatoes' vision of global politics would depend on nations enjoying genuine material security, with other nations similarly situated, and 'roughly equal' to themselves in wealth and power. This, presumably, will also engender a sense of efficacy on behalf of citizens, which might otherwise be damaged by a premature rush to global centralisation: ${ }^{42}$ 'On the way to becoming citizens of the world, they must have an opportunity to be, and they must learn to be, competent citizens of a particular state'. ${ }^{43}$ But we should be clear that the 'meat-and-potatoes' vision of world politics differs from (some) cosmopolitan visions not at the level of ideals or morality (since it shares the goal of moving closer to equality between individuals), but at the level of strategy or institutions (since it presses a strategy that Walzer believes cosmopolitans have sorely neglected). In fact the distance between Walzer and the cosmopolitans may be even less than he implies, since many if not all cosmopolitans see some role for individual states in securing global distributive justice. Either way, a world of dispersed power-with some centralisation but also a strengthening of many states - is Walzer's preferred political solution to the pervasiveness of global inequality.

The next two sections, though, seek to examine in further depth quite where this leaves us in terms of Walzer's erstwhile theoretical commitments. The first seeks to delineate the contours of his position on global egalitarianism more carefully. The second examines the relationship between this position and his emphasis on shared meanings, which appears more and more troubled. Here we confront the fact that Walzer has given no definitive account of how he now sees the relationship playing out. Whilst a definitive account could only be provided by Walzer himself, the option open to us in the meantime is to narrow down the plausible ways in which the relationship could be understood and assess the potentials and pitfalls of each approach. It will be demonstrated that there is no straightforward way in which Walzer could reconcile his defence of greater global equality and his commitment to shared understandings, even if the former is a limited commitment; indeed, the issue prompts troubling questions about Walzer's project as a whole.

\section{GLOBAL EGALITARIANISM AND NATIONAL SELF-DETERMINATION}

Would Walzer's current position count as a global egalitarian one? To produce a clear answer to this question, we need to distinguish between several views on global equality. Firstly, we might believe that all individuals across the globe are entitled to equal concern and respect. It is controversial whether, and how, this view would require us to limit global inequalities in practice, what criterion we should use in doing so, and indeed whether this would qualify as a global egalitarian view in anything other than a trivial sense. Secondly, we might believe that global inequalities along at least some dimension are pro tanto unfair, although there might be principled 


\section{Armstrong}

reasons (such as a concern for collective autonomy) which dictate that, all things considered, we should not address them. Advocates of this view will also disagree about the currency of egalitarian justice and perhaps about its site and subjects. ${ }^{44}$ Thirdly, we might believe that many if not all global inequalities are unjust all things considered and should be rectified. At least some global inequalities are sufficiently unfair that this unfairness outweighs any competing moral claims (such as collective autonomy) and should be acted upon. Note that this third view is compatible with a variety of positions on the question of who has a responsibility to do so: we might think that global inequalities are unjust, but that 'local' states bear the brunt of the responsibility for addressing them; or we might attribute some remedial responsibility to international organisations, or private citizens, just to give two examples. Fourthly, we might believe that many if not all global inequalities are unjust, that they should be addressed, and that we all share a more or less equal responsibility to address them. Whilst egalitarian entitlements might be met in a number of ways, it is when duties are both broadly shared and equally held that we may call them duties of global distributive egalitarianism.

An important point to make at the outset is that these views betoken considerable diversity, and a general reference to 'global egalitarianism' is inadequate in the face of such diversity. Although the first view may be combinable with a wide variety of political positions, it would certainly be legitimate for adherents of either our second, third, and/or fourth views to describe themselves as global egalitarians. Furthermore, any opposition between global egalitarianism and national self-determination is unhelpful unless we further specify what we take global egalitarianism to mean. A belief in our second view is obviously compatible with some degree of national self-determination. At least some self-professed global egalitarians hold that the claims of global egalitarianism can, at least on some issues, be defeated by the claims of national self-determination, with the devil residing in the detail. ${ }^{45}$ More importantly even our third view may be compatible with substantial national selfdetermination, depending upon whom we believe to be responsible for rectifying inequalities. We might believe that global inequalities are unjust, but also believe that states bear the brunt of the responsibility for making good on equality. To push the argument still further our fourth view, too, can be reconciled with some degree (and perhaps a substantial degree) of national self-determination, depending upon which goods, relations, or opportunities we would see distributed on an egalitarian basis. Global egalitarians need not, after all, be egalitarians with regards to all goods. ${ }^{46}$

All of this suggests that there is potentially some space between condemning global inequalities and calling for their correction (at least by global institutions) - and perhaps this space is inhabited by Walzer himself. Walzer does appear prepared to condemn the injustice of at least some global inequalities - indeed repeatedly so. What we need to understand is why this does not appear to lead to the advocacy of a concerted programme of global egalitarian reforms. To understand Walzer's position a little more precisely, insofar as we are able, it is useful to compare his position with that of David Miller. 
As a vocal opponent of global egalitarianism, Miller accepts our first claim (that we deserve equal respect) but is reticent about the second (that some inequalities are pro tanto unfair). His general position is that whilst at the global level we rightly make 'absolute' moral judgements about the ills of poverty, 'comparative' judgements about equality and inequality are out of place. He also suggests, to be sure, that global egalitarianism is to be rejected at least partly because it is incompatible with collective autonomy, which leaves open the possibility that inequalities are pro tanto unfair but not, all things considered, unjust. But the general position is that global inequalities are not intrinsically worrying in the first place, although some global inequalities may have deleterious effects on other values (such as that of political equality between states). ${ }^{47}$ Thus Miller can object to global inequalities on instrumental grounds, as when inequality disturbs the potential for political equality. But he will reject our third claim, at least if we read it as raising an intrinsic objection to inequality. Finally, as is well known, he does not accept the fourth either, arguing instead for a much more complex division of labour in dealing with the (by hypothesis 'absolute') issues of global poverty and human rights violations. ${ }^{48}$

I want to suggest that, for all that Walzer's position is often taken to run parallel to Miller's, it is significantly different. Unlike Miller, Walzer is not denying, now, that global equality is a valid goal. He clearly accepts our second claim: that there are inequalities which are pro tanto unfair. Inasmuch as his recent work displays a surprisingly easy acceptance that global equality is a valid goal of global governance, and that national autonomy itself is to be respected (in part) because it is instrumentally useful to secure greater individual-regarding global equality, he also appears to accept our third claim: that at least some global inequalities ought to be rectified.

What Walzer does share with some sceptics of institutional 'cosmopolitanism' is that, like Miller, he rejects our fourth claim: responsibility for tackling global inequalities must be distributed not equally, but with a view to existing institutional structures and to already-existing allegiances, though in cases of emergency or remedial justice they may fall on distant others. The language of global distributive justice plays a 'negative' role in criticising distributions, but does not commit us positively to global egalitarian duties. Instead, Walzer suggests that the institutions that exist now condition the responsibilities we have as actors. The existence of the state in particular is crucial; we therefore find an argument for a distribution of responsibilities rather like Miller's, which places the brunt of responsibility on the 'local' nation-state. ${ }^{49} \mathrm{He}$ still maintains that intervention by external powers in the affairs of (more or less) sovereign states is quite likely to go wrong, which is why pragmatically he still affirms that 'social change is best achieved from within'. ${ }^{50}$ In addition, he does suggest that individuals in effective states will bear responsibility for success and failure; national communities might be entitled to the benefits of good decision-making, and national autonomy should lead us to accept some global inequalities. ${ }^{51}$ But he simultaneously affirms that global equality is the underlying moral requirement. The resulting world of stronger states, where states are entitled to at least some of the product of good decision-making, will likely be less than fully 


\section{Armstrong}

egalitarian. But we should nevertheless accept it because at the level of strategy it represents the most egalitarian world we could realistically achieve. ${ }^{52}$

To repeat, then, a remaining point of divergence from many contemporary proponents of global justice is that, though Walzer admits that the language of global distributive justice is appropriate to diagnosing the inequalities that characterise the contemporary world, this does not, on his view, commit us to formal duties of global (re)distributive justice as the appropriate remedy. The argument remains that at the global level 'for now at least, ordinary moral principles regarding humane treatment and mutual aid do more work than any specific account of distributive justice' ${ }^{53}$ It is also suggested that what Rawls called 'natural duties' would provide the correct response to global inequalities, ${ }^{54}$ though some global transfers will be necessary. Like Rawls, he suggests that Thomas Pogge's idea of Global Resources Dividend could provide a useful mechanism for securing the goal of a world of independent, fully functioning states. ${ }^{55}$ But like Rawls, he does not quite commit himself to presenting the Dividend as an instantiation of global distributive justice in practice.

\section{GLOBAL EGALITARIANISM AND SHARED UNDERSTANDINGS}

Walzer's work is often taken to be locus classicus for the position that a metric for global egalitarianism is not available - for the view that we cannot even know what global equality means, given divergent social meanings between communities. One thing that is particularly interesting about Walzer's recent arguments about global equality, however, is that he makes no appeal therein to his erstwhile concerns about social meanings being particular to specific communities. But on what grounds might Walzer maintain, in the light of his earlier arguments, that the concept of global equality is even intelligible, or that we might develop strategies to move towards an identifiably more equal world? We need to understand whether Walzer has abandoned his scepticism about global principles of distributive justice based on the diversity of social meanings across communities. It might be suggested that Walzer's advocacy of greater global equality and his concern for respecting local meanings are not incompatible in the first place: his well-known theory of complex equality demands that we distribute goods according to shared understandings, ${ }^{56}$ and if all communities distributed goods according to their own distinct understandings, a kind of global complex equality would result. Thus for 'global equality', we should read complex equality made doubly complex as it maps across different national communities. But this cannot be right. Walzer is clear that it is a result of historical accident (largely contingent upon the separation and sheer pluralism of social spheres in modern societies) that distributing goods according to shared understandings will result, in liberal Western societies, in something we could legitimately call equality. ${ }^{57}$ Distributing goods according to shared understandings in traditional societies is just as likely to lead to hierarchy, caste privilege, and exclusion (a conclusion that was accepted, it seemed). ${ }^{58}$ So when Walzer discusses global equality, he cannot be arguing for complex equality writ globally, though he might be 
arguing for something more 'simple', such as rough equality of welfare or of resource holdings, for instance.

But can such a notion be intelligible cross-culturally? The connection between Walzer's 'internalist', interpretivist methodology, and his more recent endorsement of criteria of global egalitarianism is puzzling to say the least. Since Walzer does not provide a definitive account of the connection between the two commitments, we are confined to reconstructing the most plausible ways in which they could be reconciled and assessing their strengths and weaknesses. It is unlikely that Walzer now believes that there are no cultural obstacles to implementing global principles. More likely he believes that global distributive principles will still need cashing out in terms of the shared understandings of distinct communities. But once he would have argued that this made such distributive principles unintelligible. Now, he appears to hold that global distributive justice, and even global equality, is a meaningful concept regardless of pluralism with regard to social meanings. How are we to understand this apparent shift in position?

One way in which the commitments might be reconciled is to make a distinction between cases of injustice - which Walzer accepts that we can sometimes agree on cross-culturally, and principles of justice, on which agreement will be lacking. Walzer has argued in the past that we can cross-culturally agree on clear cases of injustice in some, usually extreme cases. But these instances are scattered, and our judgements about them, even when collected together, are too patchy to knit together into actual principles of global justice. ${ }^{59}$ But Walzer seems by now to have transcended this earlier distinction. The sweeping condemnation of global inequalities that has been mounted cannot sensibly be portrayed as referring to a disconnected series of isolated cases. Although he may not be explicitly engaged in formulating principles, neither is he on the safe ground of case-by-case analysis: some kind of step-change seems to have occurred. Perhaps - though it seems unlikely - Walzer has come to distinguish questions of ideal theory (at which level global distributive principles are appropriate) more sharply from questions of implementation. In a similar way Simon Caney responds to critics of global equality of opportunity by sharply separating the difficulty of spelling the ideal out in practice from questions about its normative desirability. ${ }^{60}$

A second-again unlikely-possibility is that shared meanings have recently emerged, perhaps as a result of cultural globalisation, which would make elaborating principles of global distributive justice a plausible enterprise across cultures. When Walzer argues for a stronger version of humanitarian intervention, he is explicit that we cannot just take a short-cut to the moral conclusions we want (a maximal account of human rights, for instance). We need to track emerging practices and institutions in international society. ${ }^{61}$ But still, he could argue more or less plausibly that the content of his new, slightly more interventionist position on human rights is supported by the evolving global human rights culture. ${ }^{62}$ That culture may be steadily shifting, and Walzer's position may reflect those shifts. But human rights inhabit, on Walzer's view, a thin, minimalist moral consensus. It would be a much 


\section{Armstrong}

more surprising conclusion if the 'thick' shared understandings necessary to sustain global egalitarianism had emerged in such a short period.

Thirdly, perhaps Walzer has been persuaded by accounts such as Martha Nussbaum's that suggest that there are some things (such as core capabilities) that all citizens need, regardless of which community they hold citizenship in, though as Nussbaum says the relevant capabilities might still be delivered differently in different cultural contexts; it might on this basis remain possible to talk meaningfully of global distributive justice and to diagnose at least the more egregious inequalities. ${ }^{63}$ Perhaps when Walzer talks of global equality, he might merely mean something rather basic in character, involving access to basic resources or capabilities; global inequalities would therefore refer to instances where individuals were deprived of these key preconditions of an adequate life. Such a conception of equality would presumably still fall prey to questions about cultural diversity, but might face such questions less acutely.

We do not know which of these arguments, if any, explain the apparent shift in position. But perhaps Walzer's discussion of global equality should not surprise us in any case: as some astute critics have pointed out, although Walzer's official definition of equality hinges solely on whether goods are distributed in accordance with their meanings or not (at least in Western societies exhibiting a plurality of spheres and distributive criteria), he has long, from time to time, assessed distributions as more or less egalitarian according to apparently more 'objective' criteria. Thus he concedes that a pluralist society in which all goods were distributed according to their distinct meanings, in their distinct spheres, might lead to the same people being 'successful' in every sphere, and concedes that this 'would certainly make for an inegalitarian society'. ${ }^{64}$ Whether or not we think such a situation probable, the point is that here Walzer concedes that even in (spherically) pluralist societies the distribution of goods according to their own appropriate principles - and thus the eradication of what he calls dominance, defined as the illicit conversion of advantage between spheres-might not lead to equality. Indeed he also admits that in less complex societies, distributing goods according to their own criteria will produce inequality, not equality. But if Walzer's official position is that equality is the absence of dominance, he must also, here, be operating with a second, background, and presumably more 'simple' conception of equality.

But what might that be? If Walzer is operating with a background conception of equality, which we can use to judge whether spherical pluralism might or might not secure equality in practice, then the status of that conception-and its seeming independence from shared understandings about the meanings of social goods - is puzzling. Perhaps it involves 'objective' sociological criteria, and tries somehow to integrate that with the more 'interpretivist' elements of his theory. But if so, it is not clear how that integration will proceed, because the two elements appear likely to run in tension. A more provocative suggestion would be that the theory of complex equality offers not a definition of equality, but a strategy for how we might (in most cases, in liberal democracies ...) deliver on the background conception of equality in practice. If this is right, the implications for the theory of complex equality are serious: 
it turns out that Walzer is really offering a method for achieving equality, however it comes to be defined (and the work of defining it remains to be done). If so, then we need to separate the levels of theorising in play more carefully. At the level of ideal theory, Walzer could be committed to a conception of equality as something like equality of welfare (to name but one possibility); this principle would be universal and non-contextual. At the level of non-ideal theory, he could then take the view that equal welfare will be served by different goods in different cultural contexts. Given that different goods contribute differently to the welfare of different individuals in different social settings - perhaps partly because they conceive of them and their value in different ways - the universal goal of equal welfare might be served best by distributing different goods according to different principles in different contexts.

This would be a troubling concession for Walzer, for it would redefine his distributive theory as a 'mere' method of application, dependent on a prior, undisclosed theory of egalitarian justice. But for present purposes the significant point is that it would render his apparently untroubled discussion of global equality and inequality less puzzling: though the theory of complex equality is not applicable across communities, there is a background conception of equality that does not depend so clearly on a given conception of social goods, and that can readily be used to appraise global inequalities. The onus would then be on Walzer to spell out the nature of this conception; he would owe us an account of what it means to discuss 'global equality' and what the relation is between that conception and (presumptively) shared understandings about the value of social goods. Just what role disagreement about the meaning of social goods across communities would then play in the delivery of global equality in practice remains to be seen.

\section{CONCLUSIONS}

We noted at the outset that Walzer has been widely identified with the view that global distributive justice, and global egalitarianism in particular, are incompatible with respecting collective autonomy, that achieving global justice would require institutions that we would have reason to be reticent about creating, and that we cannot even know what global justice means in practice in the face of cultural diversity. The first two concerns appear to remain in play is his more recent work, though they do not, if they ever did, suggest that we should reject the claims of global justice entirely. The position, instead, seems to be that we should recognise the attractions of greater global equality at the normative level, but resist the impetus to create very powerful global distributions to achieve it. Instead we should continue to place our faith in the state system, alongside some stronger-but not allpowerful - global institutions. This suggests that Walzer is a moral cosmopolitan and possibly even a kind of global egalitarian, insofar as he appears to consider the great inequalities that characterise our world as objectionable from a normative point of view. But he is certainly much less of an institutional cosmopolitan than are many other supporters of greater global equality. 


\section{Armstrong}

All of this, though, raises interesting and difficult questions about the status of the third concern, to the effect that a metric for judging global equality is unavailable. Somehow, this supposed unavailability has not prevented Walzer from criticising global inequalities and arguing that the state system, alongside stronger global institutions, ought to aim to mitigate them. This accords with the view of some global egalitarians, to the effect that despite the supposed difficulty of supplying a full and satisfactory metric for equality, it is still crushingly apparent that we live in a very unequal world, and that on a variety of significant measures - such as life expectancy, literacy rates, years in education, income per capita - these inequalities are not only identifiable but at least partly remediable. ${ }^{65}$ In the face of such inequalities, there is a question about how much more refined a metric we really need before deciding that addressing global inequality is a legitimate exercise with which we ought to charge both states and global institutions.

\section{ACKNOWLEDGEMENTS}

For helpful comments on earlier drafts of this paper, I would like to thank Helena De Bres, Andrew Mason, Adam Swift, and Lea Ypi. The reviewers for this journal also offered useful guidance, and I should offer special thanks to Michael Walzer, who took the time to provide an encouraging and instructive response.

\section{NOTES}

1. David Miller, National Responsibility and Global fustice (Oxford: Oxford University Press, 2007); John Rawls, The Law of Peoples, with The Idea of Public Reason Revisited (Cambridge, MA: Harvard University Press, 1999).

2. See e.g. Miller, National Responsibility, 78; David Miller, Citizenship and National Identity (Cambridge: Polity, 2000), 169; David Miller, On Nationality (Oxford: Oxford University Press, 1995), 192.

3. John Rawls, A Theory of fustice (Cambridge, MA: Harvard University Press, 1971).

4. See, for instance, Charles Beitz, Political Theory and International Relations (Princeton: Princeton University Press, 1979); Thomas Pogge, Realizing Rawls (Ithaca: Cornell University Press, 1989).

5. Beitz advanced arguments for both a Global Difference Principle and a resource redistribution principle in Political Theory and International Relations. Charles Jones, for instance, advocated a more minimalist cosmopolitan account focussing on the delivery of human rights (including the right to subsistence); Charles Jones, Global fustice: Defending Cosmopolitanism (Oxford: Oxford University Press, 2001). For an approach focusing (in part) on the satisfaction of basic needs, see Gillian Brock, Global fustice: A Cosmopolitan Account (Oxford: Oxford University Press, 2009).

6. Rawls, The Law of Peoples.

7. Michael Walzer, Thinking Politically: Essays in Political Theory, ed. David Miller (London: Yale University Press, 2007), 192.

8. Walzer, Spheres of Fustice: A Defense of Pluralism and Equality (New York: Basic Books, 1983), 29. For some critical responses to Walzer's interpretivist methodology, see David Miller and Michael Walzer eds., Pluralism, fustice and Equality (Oxford: Oxford University Press) - and especially the chapters by Barry and Arneson. 
9. Michael Walzer, The Company of Critics: Social Criticism and Political Commitment in the Twentieth Century (New York: Basic Books, 1988), 99.

10. Michael Walzer, Thick and Thin: Moral Argument at Home and Abroad (London: University of Notre Dame Press, 1994), 46.

11. Michael Walzer, Interpretation and Social Criticism (London: Harvard University Press, 1987), 3-32.

12. Walzer, Thinking Politically, 22-37, 219-36.

13. Ibid., 183-99.

14. Michael Walzer, On Toleration (London: Yale University Press, 1997), 21.

15. Walzer, Spheres of fustice, 29; see also Thinking Politically, 233-34.

16. Spheres of fustice, 30; Walzer, Arguing About War (London: Yale University Press, 2004), 176.

17. John Rawls, The Law of Peoples, 37, 57.

18. This theme of The Law of Peoples is particularly emphasised in Leif Wenar, 'Why Rawls is Not a Cosmopolitan Egalitarian', in Rawls's Law of Peoples: A Realistic Utopia? eds. Rex Martin and David Reidy (Oxford: Blackwell, 2006), 95-113.

19. David Miller, National Responsibility, 56-68.

20. For the defence, see Simon Caney, 'Cosmopolitan Justice and Equalizing Opportunities', Metaphilosophy 32, nos. 1-2 (2001): 113-34; Darrel Moellendorf, 'Equality of Opportunity Globalized', Canadian Fournal of Law and Furisprudence 19, no. 2 (2006): 301-18. For criticisms, see Gillian Brock, 'Egalitarianism, Ideals and Cosmopolitan Justice', Philosophical Forum 36 (2005): 1-30; Margaret Moore, 'Justice Within Different Borders: A Review of Simon Caney's Global Political Theory', fournal of Global Ethics 3, no. 2 (2007): 255-68.

21. Quoted in Walzer, Spheres of Fustice, 45.

22. Ibid., 47.

23. Ibid., 48.

24. Arguing About War, xiii; see also Thinking Politically, 251-63.

25. Arguing About War, 187.

26. Michael Walzer, Politics and Passion: Towards a More Egalitarian Liberalism (London: Yale University Press, 2004), 131.

27. Arguing About War, 171.

28. Ibid., 177.

29. Ibid., 177, 191.

30. Charles Beitz, 'International Liberalism and Distributive Justice: A Survey of Recent Thought', World Politics 51, no. 2 (1999): 269-96.

31. Walzer, Thinking Politically, 53-67.

32. Walzer, Politics and Passion, 33.

33. Ibid., 29-32. Compare with Rawls's position (in $A$ Theory of fustice) that a just distribution of primary social goods would go a considerable way towards ending the evils of racism. But unlike Walzer, Rawls does not appear to suggest that it is the material advancement of the group or its associations which is likely to be key here.

34. Walzer, Politics and Passion, 38, 42.

35. Ibid., 135-37.

36. This criticism is too sweeping. There are cosmopolitan views that do attach significance to the transformation of domestic institutions as a key-perhaps the key-cosmopolitan method. See, for instance, Lea Ypi, 'Statist Cosmopolitanism', fournal of Political Philosophy 16, no. 1 (2008): 48-71.

37. Walzer, Arguing About War, 179-80.

38. Walzer, Politics and Passion, xiii.

39. Ibid., 135.

40. See e.g. Michael Walzer, 'The Reform of the International System', in Studies in War and Peace, ed. Ø. Østerud (Oslo: Norwegian University Press, 1986), 227-250, at 232. 


\section{Armstrong}

41. Walzer, Politics and Passion, 176, n.6. Pogge's scheme would levy a very low tax on the extraction of natural resources, with the proceeds accruing to a global fund. This fund would then be used to raise all persons above the level of severe poverty (i.e. it would ensure that all could subsist on more than two dollars a day, adjusted for purchasing power parity). See Thomas Pogge, World Poverty and Human Rights (Cambridge: Polity Press, 2002), Chapter 8, 196-215.

42. Walzer, Politics and Passion, 38, 42; Cf. Christopher Bertram, 'Global Justice, Moral Development and Democracy', in The Political Philosophy of Cosmopolitanism, in eds. Gillian Brock and Harry Brighouse (Cambridge: Cambridge University Press, 2005), 75-91.

43. Walzer, Politics and Passion, 138.

44. For an account of the diversity of global egalitarian arguments, see Chris Armstrong, 'Global Egalitarianism', Philosophy Compass 3 (2008), http://www.blackwell-compass.com/subject/ philosophy/article_view?article_id=phco_articles_bpl189 (accessed 24th June 2010).

45. For a fuller argument to this effect see Chris Armstrong, 'National Self-Determination, Global Equality and Moral Arbitrariness', fournal of Political Philosophy 18, no. 3 (2010): 313-34.

46. Indeed some global egalitarian accounts might hold that nation-states themselves are both the subjects and the agents of egalitarian justice - in which case they might even presume a world of self-determining nation-states. See the discussion in Alexander Cappelen, 'Responsibility and International Distributive Justice', in Real World Fustice, eds. Andreas Follesdal and Thomas Pogge (Dordrecht: Springer, 2005), 215-28.

47. For the view that 'comparative' principles such as equality out of place on the global scale, see e.g. David Miller, Principles of Social fustice (Cambridge, MA: Harvard University Press, 1999), 19. For the argument about political equality, see David Miller, 'Collective Responsibility and International Inequality in The Law of Peoples', in Rawls's Law of Peoples: A Realistic Utopia? eds. Rex Martin and David Reidy (Oxford: Blackwell, 2006), 191-205. For a general account of 'indirect' or instrumental reasons for objecting to global inequalities, see Charles Beitz, 'Does Global Inequality Matter?' Metaphilosophy 32, no. 1 (2001): 95-112.

48. Miller, National Responsibility.

49. Walzer, Thinking Politically, 252-59, at p.254. Miller argues for a complex approach to the distribution of responsibility for dealing with global poverty, which might take into account our contribution to the existence of that poverty, our capacity to deal with it, and our proximity to it, for example. See chapter 9 of his National Responsibility.

50. Walzer, Thinking Politically, 238.

51. Ibid., 136.

52. Ibid., 139.

53. Michael Walzer, 'Response,' in David Miller and Michael Walzer, eds. Pluralism, Fustice and Equality (Oxford: Oxford University Press, 1995), pp. 281-97.

54. Walzer, Thinking Politically, 308.

55. Rawls suggested that the implications of his 'Duty of Assistance' and Pogge's Global Resources Dividend could end up being 'much the same, with largely practical matters of taxation and administration to distinguish between them', Law of Peoples, 119.

56. Walzer, Spheres of Fustice.

57. Ibid., 26-28.

58. Walzer accepts that his method of staying true to shared meanings will result in hierarchy and exclusion in such societies, because 'we can only talk of a regime of complex equality when there are many boundaries to defend'. Ibid., 28. In a (liberal) society in which the meanings of many goods are autonomous, their separate distribution will lead to a situation where the potential sources of social power and domination are disconnected, and we are in that sense insulated from the possibility that monopolies might be multiplied across the different 
spheres of justice. By contrast, 'In a society where social meanings are integrated and hierarchical, justice will come to the aid of inequality'. Ibid., 313.

59. Walzer, Thick and Thin, 1-4.

60. Simon Caney, 'Justice, Borders and the Cosmopolitan Ideal: A Reply to Two Critics', Fournal of Global Ethics 3, no. 2 (2007): 269-276, at 271.

61. Walzer, Thinking Politically, 254.

62. For an argument that 'Practice is now far ahead of theory' in some respects, see Henry Shue, 'Thickening Convergence: Human Rights and Cultural Diversity,' in The Ethics of Assistance, ed. Deen Chatterjee (Cambridge: Cambridge University Press, 2004), 217-41, at 233.

63. Martha Nussbaum, 'Beyond the Social Contract: Capabilities and Global Justice', in The Political Philosophy of Cosmopolitanism, eds. Gillian Brock and Harry Brighouse (Cambridge: Cambridge University Press, 2005), 196-218, at 211.

64. Walzer, Spheres of Fustice, 20.

65. See also Leif Wenar, 'Human Rights and Equality in the Work of David Miller', Critical Review of International Social and Political Philosophy 11, no. 4 (2008): 401-11. 